\title{
Forging Condition for Removing Porosities in the Hybrid Casting and Forging Process of 7075 Aluminum Alloy Casting
}

\author{
Fung-Chi Chang ${ }^{1}$, Weng-Sing Hwang ${ }^{1, *}$, Chung-Ham Lee ${ }^{1}$, Chun-Fu Wu ${ }^{2}$ and Jin-Bin Yang ${ }^{3}$ \\ ${ }^{1}$ Department of Materials Science and Engineering, National Cheng Kung University, Tainan, Taiwan, R. O. China \\ ${ }^{2}$ Metal Processing Department, Metal Industries Research and Development Center, Kaohsiung, Taiwan, R. O. China \\ ${ }^{3}$ Department of Mechanical and Automation Engineering, National Kaohsiung First University of Science and Technology, \\ Kaohsiung, Taiwan, R. O. China
}

In this study, the ranges of compression ratio for the successful implementation of hybrid casting and forging process for 7075 aluminum alloy are investigated. Hybrid casting and forging process combines the advantages of casting and forging processes. In this process, a near net shape preform is first cast and the casting is subsequently forged. The casting defects such as shrinkage porosity can be eliminated by forging and the number of forging steps can also be reduced. Therefore, the production cost can be reduced. In this study, castings with stepwise cross section are die cast with 7075 aluminum alloy. The stepwise cross section has three different thicknesses, which are $15 \mathrm{~mm}, 10 \mathrm{~mm}$ and $5 \mathrm{~mm}$. The aim of this study is to obtain how high compression ratio is required to eliminate the porosities inside the preform castings with various thicknesses, where porosity contents are different, and what are the maximum compression ratios that can be tolerated before these preform castings fail. These data are crucial to the design of the preform casting for the hybrid casting and forging process. The experimental results show that for 7075 aluminum alloy, it requires a compression ratio of $30 \%$ to eliminate all the porosities in the casting section of $5 \mathrm{~mm}$ in thickness and a maximum compression ratio of $44 \%$ can be tolerated. For the casting section of $10 \mathrm{~mm}$ in thickness, it requires $41 \%$ of compression ratio to eliminate all the porosities and a maximum compression ratio of $64 \%$ can be tolerated. For the casting section of $15 \mathrm{~mm}$ in thickness, it requires $52 \%$ of compression ratio to eliminate all the porosities and a maximum compression ratio of $64 \%$ can be tolerated.

(Received September 25, 2003; Accepted April 22, 2004)

Keywords: hybrid casting and forging process, 7075 aluminum alloy, compression ratio, porosity

\section{Introduction}

Hybrid casting and forging process combines the advantages of casting and forging processes. In this process, a near net shape preform is first cast and the casting is subsequently forged. The casting defects such as shrinkage porosity can be eliminated by forging and the number of forging steps can also be reduced. Therefore, the production cost can be reduced. Basically, hybrid casting and forging process can be approached in two ways. One is to use forging alloys. In this approach, usually more porosities are formed in the casting and higher compression ratio is needed to eliminate all the porosities in subsequent forging, which is possible due to better forgeability of forging alloy. The other approach is to use casting alloys. In this approach, usually less porosities are formed in the casting and lower compression ratio is needed to eliminate all the porosities in subsequent forging, which is a required condition due to poor forgeability of casting alloy. Two critical compression ratios are considered in this study. One is the compression ratio required to eliminate the porosities inside the preform casting. The other is the compression ratio causing the preform casting to fail. For both approaches, these two compression ratios are very important data since the preform casting must be designed in such a way that the required compression ratio from the preform to the final product is enough to eliminate all the casting porosities and is still under its failure limit.

In this study, the first approach is employed. The forging alloy used is 7075 aluminum alloy. 7075 aluminum alloy is commonly used to manufacture structural parts of aircraft

*To whom all correspondences should be addressed. Corresponding author, E-mail: wshwang@mail.ncku.edu.tw and other structural parts, which require high strength. The work load is reduced when it is forged at high temperature, where the flow stress of the alloy during plastic deformation is lowered and work hardening is also alleviated. ${ }^{1)}$ Moreover, high temperature and high strain rate can enhance the occurrence of dynamic recrystallization, which results in smaller grain size. In turn, it makes the plastic flow easier. ${ }^{2)}$ For the hybrid casting and forging process, the employment of 2014 aluminum alloy, which is also a forging alloy, had been studied. ${ }^{3)}$ It was found that by adding Al-Ti-B or Al-B alloy, which is the grain refiner, in the alloy, the grain size of the casting was decreased and the amount of porosities was reduced. After forging, the ductility and strength of the casting were substantially improved.

The purpose of this study is to obtain how high compression ratio is required to eliminate the porosities inside the preform castings with various thicknesses, where porosity contents are different, and what are the maximum compression ratios before these preform castings fail for 7075 aluminum alloy. Preform castings with stepwise cross section are die cast to obtain casting specimens with three different thicknesses, which are $15 \mathrm{~mm}, 10 \mathrm{~mm}$ and $5 \mathrm{~mm}$. Compression tests are then conducted for the casting samples with various thicknesses to obtain the two concerned compression ratios. These data are crucial to the design of the preform casting for the hybrid casting and forging process.

\section{Experimental Method}

\subsection{Design of die casting die}

As described earlier, 7075 aluminum alloy castings with stepwise cross section were die cast. The idea is to have 


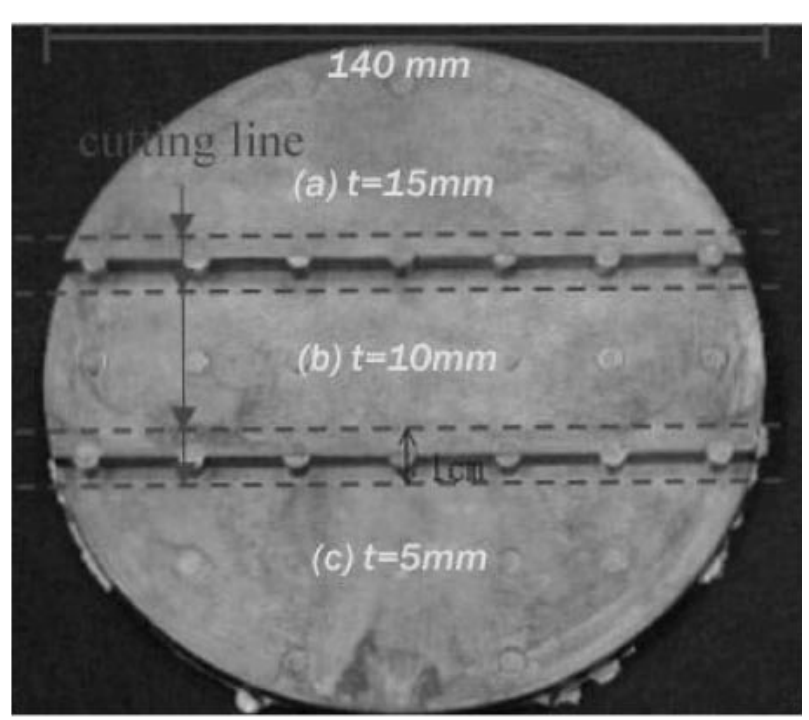

Fig. 1 Geometry and dimensions of the casting.

casting specimens with various porosity contents while all other features related to the casting property remain the same. To achieve this goal, the die casting die must be carefully designed to eliminate the air entrapment so that the porosity in the casting can be mainly attributed to solidification shrinkage. ${ }^{4)}$ In this study, a die filling analysis system was employed to evaluate the air entrapment conditions for various die designs. ${ }^{5)}$ A suitable die design was then obtained to avoid most of the air entrapment.

\subsection{Die casting experiment and specimen preparation}

With the die casting die designed and fabricated, die castings were then made using a ZDC-150T-V2BP die casting machine with all the necessary treatments such as degassing of the aluminum melt and control of die temperature to produce sound castings. The casting temperature was around $923 \mathrm{~K}$. Subsequently, the casting was cut with a CNC wire cutter into three pieces, which correspond to the three thicknesses as shown in Fig. 1. The amount of porosity and averaged pore diameter of the casting piece were then measured by using an image analysis software; named Optimas. It should be noted that shrinkage porosity is usually not round. However, to quantitatively describe the seriousness of the porosity condition, the diameter of a pore, which has an equivalent area to the porosity, was then employed. Each casting piece was further cut into three specimens for subsequent forging experiments.

\subsection{Forging experiment}

The casting specimens of three thicknesses were then subjected to forging experiment to obtain the forgeability data. The steps for the forging experiment are as follows.

(1) Measure the height and density of the specimen.

(2) Heat the specimen to $673 \mathrm{~K}$ and hold at the temperature for 20 minutes.

(3) Take the specimen out from the furnace and compress it to a pre-determined height using a $650 \mathrm{~T}$ forging machine, where the upper die and lower die are preheated to $523 \sim 573 \mathrm{~K}$.
(4) Cool the specimen to room temperature and measure its height and density.

\subsection{Porosity measurement and compression ratio cal- culation}

The formation of porosities in the casting and subsequent elimination of the porosities by forging are major concerns in the development of the hybrid casting and forging process. It then requires a mean to quantify the amount of porosities in the specimen. The method employed in this study to measure the amount of porosities in the specimen is described as follows.

$$
\text { Porosity }(\%)=\left(\rho_{\text {theory }}-\rho_{\text {solid }}\right) / \rho_{\text {theory }} \times 100 \%
$$

where

$\rho_{\text {solid }}$ : density of the specimen, $\mathrm{kg} / \mathrm{m}^{3}$,

$\rho_{\text {theory }}$ : theoretical density of 7075 aluminum alloy $\left(2,810 \mathrm{~kg} / \mathrm{m}^{3}\right)$.

The density of the specimen was measured based on the Archmedes Principle, which can be described as follows. ${ }^{6}$

$$
\rho_{\text {solid }}=W_{\text {air }} / V_{\text {solid }}
$$

and

$$
V_{\text {solid }}=\left(W_{\text {air }}-W_{\text {water }}\right) / \rho_{\text {water }}
$$

where

$W_{\text {air }}:$ mass of the sample in air, $\mathrm{kg}$,

$W_{\text {water }}$ : mass of sample in water, $\mathrm{kg}$,

$\rho_{\text {water }}$ : density of water, $\mathrm{kg} / \mathrm{m}^{3}$,

$V_{\text {solid }}$ : volume of the sample, $\mathrm{m}^{3}$.

The purpose of this study is to obtain the compression ratio range for the hybrid cast/forge processing. Therefore, it is essential to calculate the compression ratio during the forging step. The compression ratio of the specimen was calculated as,

$$
\text { Compression ratio }(\%)=\left(H_{\mathrm{O}}-H_{\mathrm{f}}\right) / H_{\mathrm{O}} \times 100 \%
$$

where

$H_{\mathrm{O}}$ : thickness of the specimen before forging $(\mathrm{mm})$, $H_{\mathrm{f}}$ : thickness of the specimen after forging $(\mathrm{mm})$.

\section{Results and Discussion}

In this study, the hybrid casting and forging process was developed for the 7075 aluminum alloy. The chemical composition of the alloy was measured and is shown in Table 1.7)

\subsection{Porosity contents in die cast preforms}

The casting has a stepwise cross section with three different thicknesses, which are $15 \mathrm{~mm}, 10 \mathrm{~mm}$ and $5 \mathrm{~mm}$. It is round with a diameter of $140 \mathrm{~mm}$ and the geometry and dimensions of the casting are shown in Fig. 1. The weight of the casting is around $400 \mathrm{~g}$.

Table 1 Chemical composition of 7075 aluminum alloy (mass\%).

\begin{tabular}{cccc}
\hline $\mathrm{Al}$ & $\mathrm{Zn}$ & $\mathrm{Mg}$ & $\mathrm{Cu}$ \\
\hline Bal. & 5.6 & 2.5 & 1.6 \\
\hline
\end{tabular}




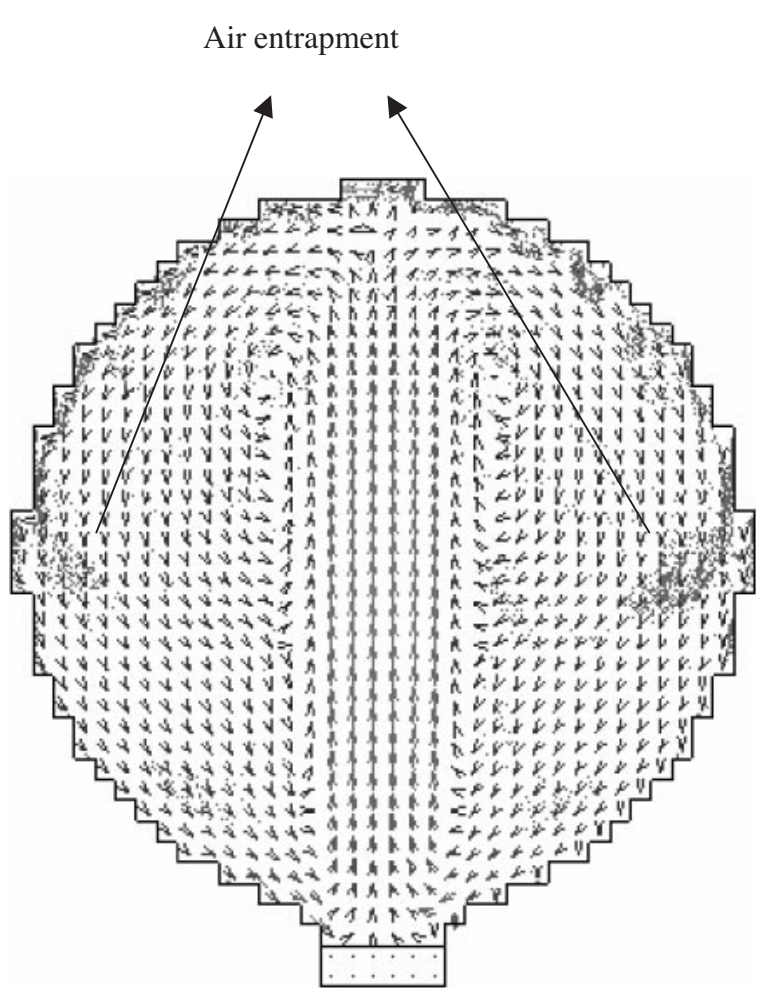

Fig. 2 Condition of air entrapment in the casting.

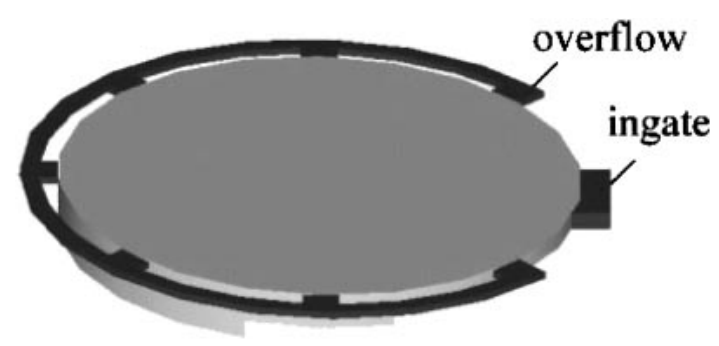

Fig. 3 A schematic sketch of the revised die design.

As described earlier, the die design, which assures that the casting is free from air entrapment, is obtained through the aid of a die filling simulation system. The first design is simply to have an ingate; $2 \mathrm{~mm}$ in length, $5 \mathrm{~mm}$ in width, and $5 \mathrm{~mm}$ in height, located at the $5 \mathrm{~mm}$ section. The die filling pattern and the extent of air entrapment were simulated and the results are shown in Fig. 2. It can be seen that the condition of air entrapment is rather serious. Then, a ring, which had an inner diameter of $150 \mathrm{~mm}$, outer diameter of $160 \mathrm{~mm}$, and $2 \mathrm{~mm}$ in height, was added around the casting as the overflow system. A schematic sketch of the revised die is shown in Fig. 3. As shown by the simulated results in Fig. 4, the condition of air entrapment is substantially reduced.

The die casting preforms were then produced using the revised die design. The casting was then cut into three pieces and the porosity contents of the casting pieces were measured. The cutting locations are shown in Fig. 1. The average diameter of the porosity on the cut surface for the $15 \mathrm{~mm}$ piece shown in Fig. 5(a) was $1.26 \mathrm{~mm}$. The average diameter of the porosity for the $10 \mathrm{~mm}$ piece on the cut

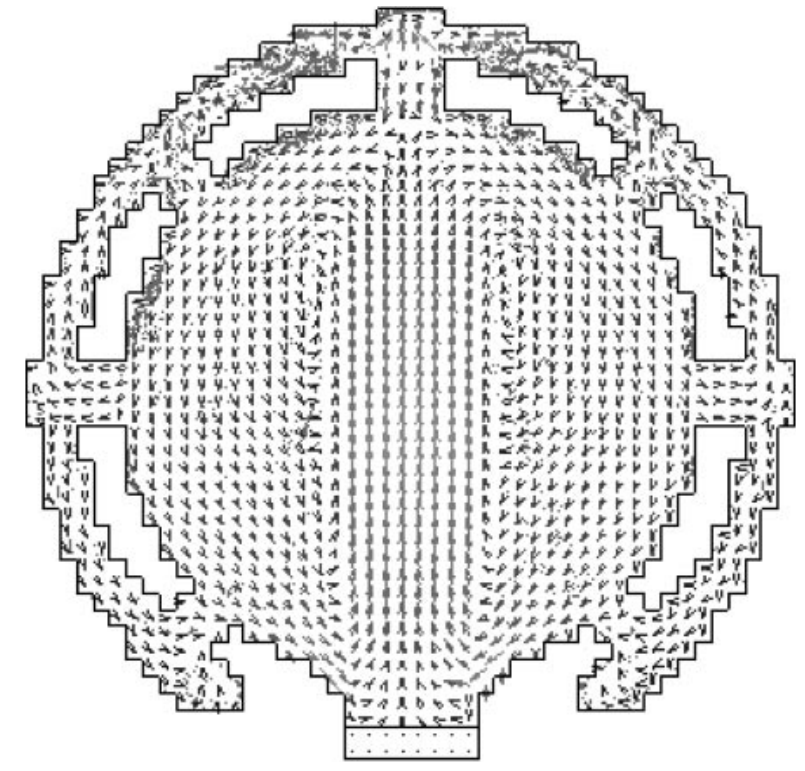

Fig. 4 Condition of air entrapment in the casting with the revised die design.

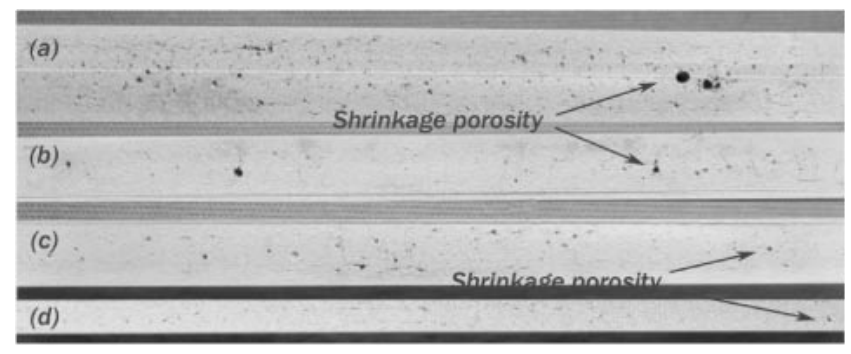

Fig. 5 Condition of shrinkage porosity for the casting of (a) $15 \mathrm{~mm}$ in thickness, (b) $10 \mathrm{~mm}$ in thickness (next to the $15 \mathrm{~mm}$ section), (c) $10 \mathrm{~mm}$ in thickness (next to the $5 \mathrm{~mm}$ section), and (d) $5 \mathrm{~mm}$ in thickness.

surface, next to the $15 \mathrm{~mm}$ section, shown in Fig. 5(b) was $0.79 \mathrm{~mm}$. The average diameter of the porosity for the $10 \mathrm{~mm}$ piece on the cut surface, next to the $5 \mathrm{~mm}$ section, shown in Fig. $5(\mathrm{c})$ was $0.68 \mathrm{~mm}$. The average diameter of the porosity on the cut surface for the $5 \mathrm{~mm}$ piece shown in Fig. 5(d) was $0.40 \mathrm{~mm}$.

\subsection{Results of the forging experiments}

Cylindrical specimens were cut from each casting section. The specimens have diameters equal to their heights. The height and density of each specimen was measured and then forging experiment was conducted.

After each forging experiment, the height and density of the specimen was measured. It should be noted that each casting section was further cut into three samples. The densities and porosity contents of the samples are then plotted against compression ratios. The results are shown in Fig. 6 for the three samples. The results show that the densities of the samples with a compression ratio around 50\% are close to the theoretical density. The figure shows that before compression ratio reaches $25 \%$, the density increases significantly and thus porosity content decreases. As compression ratio reaches $40 \%$, only slight densification can be 


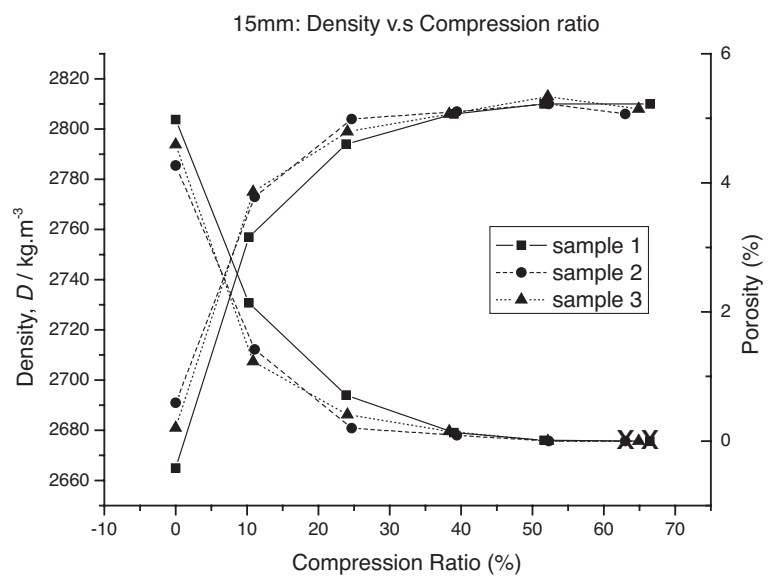

Fig. 6 The densities and porosities corresponding to various compression ratios for the casting specimen of $15 \mathrm{~mm}$ in thickness.

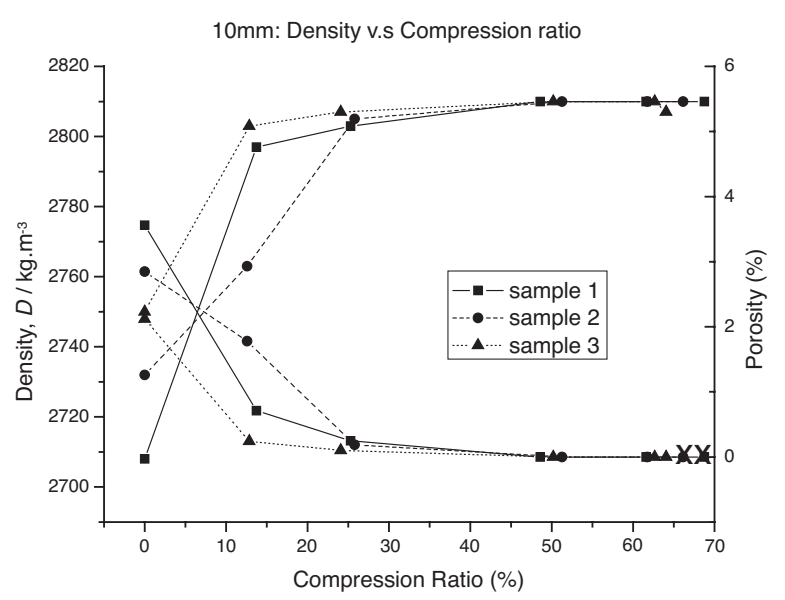

Fig. 7 The densities and porosities corresponding to various compression ratios for the casting specimen of $10 \mathrm{~mm}$ in thickness.

achieved. Through data interpolation, it shows that for the samples 1-3 to be compressed to their theoretical density, they need compression ratios of $54 \%, 52 \%$, and $49 \%$, respectively. An average compression ratio of approximately $52 \%$ is then required to eliminate all the porosities in the casting section of $15 \mathrm{~mm}$ in thickness. As density of the specimen reaches theoretical density after certain amount of compression and further compression applied on the specimen exhibits a decrease in density, it is taken as the notion that fracture has occurred on that particular specimen. It then shows that the maximum compression ratio they can withstand without fracture is around 64\%.

The densities and porosity contents versus compression ratios of the samples are shown in Fig. 7. The results show that as compression ratio is smaller than $10 \%$, the density increases significantly with compression. As compression ratio reaches $25 \%$, only slight densification can be achieved. Through data interpolation, it shows that for the samples 1-3 to be compressed to their theoretical density, they need compression ratios of $40 \%, 39 \%$, and $43 \%$, respectively. An average compression ratio of approximately $41 \%$ is then required to eliminate all the porosities in the casting section

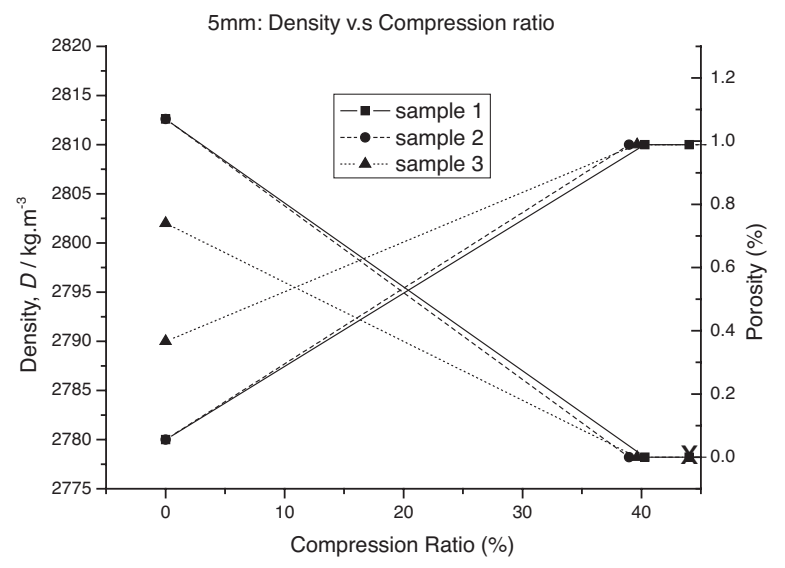

Fig. 8 The densities and porosities corresponding to various compression ratios for the casting specimen of $5 \mathrm{~mm}$ in thickness.

of $10 \mathrm{~mm}$ in thickness. It also shows that the maximum compression ratio they can withstand without fracture is between 62 and $66 \%$.

The densities and porosity contents versus compression ratios of the samples are shown in Fig. 8. The results show that the densities of the samples all reach the theoretical density after the first compression. Comparing the data for $15 \mathrm{~mm}$ and $10 \mathrm{~mm}$ in thicknesses, the average compression ratio to eliminate all the porosities is decreased from $52 \%$ to $41 \%$. It is assumed that the same tendency can be extended to $5 \mathrm{~mm}$. Therefore, an average compression ratio of $30 \%$ is required to eliminate all the porosities in the casting section of $5 \mathrm{~mm}$ in thickness. It also shows that the maximum compression ratio they can withstand without fracture is less than $44 \%$.

\section{Conclusion}

Fundamental data, which include compression ratios required to eliminate the porosities inside the preform castings with various thicknesses and maximum compression ratios before these preform castings fail, were obtained in this study for the development of hybrid casting and forging process for 7075 aluminum alloy.

Castings with round shape and stepwise cross section were die cast to obtain casting specimens with three different thicknesses, which have different porosity contents. Forging experiments were then conducted to obtain the needed data. The results show that for 7075 aluminum alloy, it requires a compression ratio of $30 \%$ to eliminate all the porosities in the casting section of $5 \mathrm{~mm}$ in thickness, which has an initial average porosity diameter of $0.40 \mathrm{~mm}$, and it can withstand a maximum compression ratio of $44 \%$. For the casting section of $10 \mathrm{~mm}$ in thickness, which has an initial average porosity diameter between $0.79 \mathrm{~mm}$ and $0.68 \mathrm{~mm}$, it requires a compression ratio of $41 \%$ to eliminate all the porosities and a maximum compression ratio of $64 \%$ can be tolerated. For the casting section of $15 \mathrm{~mm}$ in thickness, which has an initial average porosity diameter of $1.26 \mathrm{~mm}$, it requires $52 \%$ of compression ratio to eliminate all the porosities and it can withstand a maximum compression ratio of $64 \%$. 


\section{Acknowledgements}

The authors would like to express their gratitude to the Metal Industries Research and Development Center in Taiwan for the financial and technical supports extended to this study.

\section{REFERENCES}

1) W. S. Lee and W. C. Sue: Journal of Materials Processing Technology
100 (2000) 116-122.

2) T. Sakai and X. Yang: Mater. Sci. Eng. (1997) 857-860.

3) R. L. Mai: M.S. Thesis, National Cheng Kung University, Tainan, Taiwan, 1991.

4) T. H. Han and W. S. Hwang: Transactions of the Japan Foundrymen's Society 14 (1995) 69-88.

5) J. H. Kuo, Y. F. Chiu, T. S. Wang, M. C. Kuo and W. S. Hwang: AFS Trans. 109 (1999) 793-802.

6) J. H. Kuo, Y. F. Chen, P. J. Chen, W. S. Hwang and H. S. Wang: AFS Trans. 111 (2001) 461-468.

7) ASM Metals Handbook, Volume 2 (1990) 115-116. 